\title{
The Creep Deformation Mechanisms of Nickel Base Superalloy René 104
}

\author{
R.R. Unocic,* P.M. Sarosi,* G.B. Viswanathan,* M.J. Mills, ${ }^{*}$ and D.A. Whitis** \\ * Department of Materials Science and Engineering, The Ohio State University, Columbus, $\mathrm{OH}$ \\ ** G.E. Aircraft Engines, Cincinnati, $\mathrm{OH}$
}

\begin{abstract}
The deformation substructures developed during creep of a newly developed polycrystalline Nibased superalloy, René 104, consisting of a bimodal $\gamma^{\prime}$ precipitate size distribution, was characterized using diffraction-contrast transmission electron microscopy (TEM). Increasing temperature and decreasing stress marked a transition in the deformation mechanism from microtwinning, through superlattice stacking fault formation, to dislocation climb/bypass.
\end{abstract}

\section{Introduction}

Nickel-based superalloys are an important class of engineering materials in that they were developed specifically for service conditions that require elevated-temperature strength and resistance to creep, thermal and mechanical fatigue, and oxidation [1-2]. The strength and creep resistance of these alloys are largely attributable to the ordered intermetallic $\gamma^{\prime}$ phase, and to a lesser extent to solidsolution hardening in the $\gamma$ matrix phase.

The purpose of this study was to evaluate the creep deformation behavior of Ni-based superalloy René 104 and to characterize the deformation structures that form during creep. Energy-filtered TEM (EFTEM) imaging was conducted for $\gamma^{\prime}$ microstructural characterization. The deformation substructures that formed as a result of creep were characterized via diffraction-contrast TEM.

\section{Materials and Experimental Procedure}

Ni-based superalloy René 104, formerly known as ME3, was developed through NASA's (HSR/EPM) program through collaboration with GEAE and Pratt \& Whitney [3]. Tensile creep specimens were machined from actual scaled up disk forgings about varying locations and given a supersolvus heat treatment in order to manipulate the $\gamma^{\prime}$ precipitate morphology into a bimodal secondary and tertiary $\gamma^{\prime}$ precipitate distribution. Constant load, uniaxial creep tests were then carried out at temperatures between 677 and $815^{\circ} \mathrm{C}$ and stress levels between 345 and $742 \mathrm{MPa}$.

Foils were prepared from the gauge length by sectioning the specimens at an angle of $\sim 45^{\circ}$ with respect to the tensile axis. TEM 3-mm disks were slurry drilled, ground to a thickness of $\sim 100 \mu \mathrm{m}$, then electropolished in an electrolyte containing $10 \% \mathrm{HClO}_{4}$ and $90 \%$ Methanol at $-40{ }^{\circ} \mathrm{C} / 15 \mathrm{~V}$. The deformation substructures that formed during creep experiments were characterized using a Philips CM200 TEM. EFTEM imaging (Fig. 1a) was performed on TEM foils to image and characterize the finer tertiary $\gamma^{\prime}$ precipitates using a FEI Tecnai TF20 TEM [4].

\section{Results and Discussion}

A preliminary TEM investigation of the deformation substructures that formed during creep of René 104 was conducted. The microstructure consisted of a bimodal $\gamma^{\prime}$ distribution. Distinct deformation mechanisms were identified for each temperature regime. The deformation mechanism of samples crept at $677^{\circ} \mathrm{C}$ and $690 \mathrm{MPa}$ was found to be that of microtwinning. Fig. $1 \mathrm{~b}$ depicts the microtwins viewed in the edge-on orientation. The inset selected area diffraction pattern about the [011] zone axis yields strong evidence that the observed defect structures are microtwins with reflections that 
correspond to fundamental, superlattice, and twin reflection. Samples crept at $704^{\circ} \mathrm{C}$ differed in mechanism. Fig 1c. depicts a shearing configuration in which $\gamma^{\prime}$ precipitates and/or $\gamma / \gamma^{\prime}$ are being sheared. These shearing configurations result in either a superlattice intrinsic (SISF) or superlattice extrinsic (SESF) stacking fault being formed in the matrix and/or $\gamma^{\prime}$ precipitates. Additional work is in progress to identify the nature of the fault contrast and the partial dislocations that are responsible for the $\gamma / \gamma^{\prime}$ shearing. In the temperature regime $760-815^{\circ} \mathrm{C}$, there appears to be a mixture of deformation mechanisms operating; however, climb/bypass appears to be activated in this regime (Fig. 1d). Characteristic of this dislocation climb/bypass mode are $1 / 2<110>$-type matrix dislocations that bypass $\gamma^{\prime}$ precipitates by thermally activated climb. This mechanism is presumed to be operative at these elevated temperatures during prolonged exposure where dissolution of the tertiary $\gamma^{\prime}$ precipitates has occurred.

\section{Summary}

The creep deformation mechanisms in the newly developed René 104 superalloy were identified through TEM characterization. The observations show clear transitions in deformation mode as a function of stress and temperature. These dependencies must be considered and incorporated in the development of physically based models for creep of this and similar superalloys.

\section{References}

[1] E.F. Bradley, Superalloys: A Technical Guide, ASM International (1988).

[2] M.J. Donachie, Superalloys, American Society for Metals (1984).

[3] T.P. Gabb et al., NASA/TM-2002-211796 (2002).

[4] P.M. Sarosi et al., Ultramicroscopy, in press.

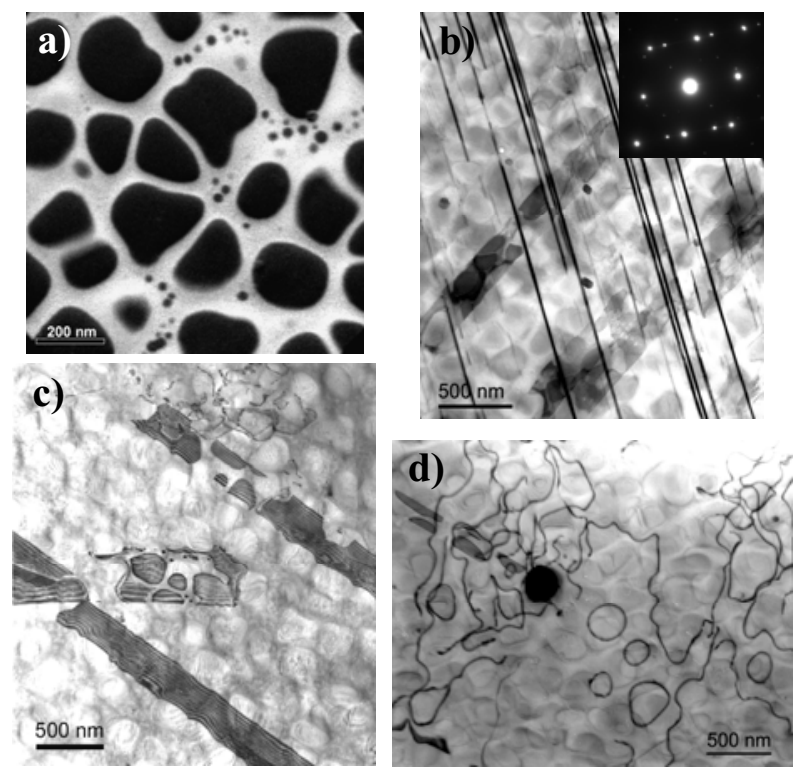

FIG 1. TEM images of René 104 Ni-based superalloy: a) EFTEM image depicting bimodal $\gamma^{\prime}$ distribution; and b) microtwinning c) superlattice stacking fault shear and d) climb/bypass creep deformation substructures that form under different stress and temperature regimes. See text for details. 